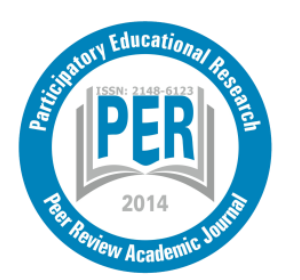

Participatory Educational Research (PER)

Vol. 8(4), pp. 409-425, December 2021

Available online at http://www.perjournal.com

ISSN: 2148-6123

http://dx.doi.org/10.17275/per.97.51.8.4

\title{
Temperate but not Brave Children: Character Strengths in Life Science Course Curriculum ${ }^{1}$
}

\author{
Ferat Y1lmaz \\ Department of Primary Education, Dicle University, Diyarbakir, Turkey \\ ORCID: 0000-0002-4947-5416
}

Article history

Received:

05.10 .2020

Received in revised form: 03.05.2021

Accepted:

14.05.2021

Key words:

Character strengths,

Virtues,

Life science course curriculum
Character encompasses six basic virtues. These virtues can be listed as wisdom, courage, humanity, justice, temperance, and transcendence. Each virtue comprises various character strengths that are creativity, curiosity, open-mindedness, love of learning, perspective, honesty, bravery, perseverance, zest, kindness, love, social intelligence, fairness, leadership, citizenship, forgiveness, modesty, prudence, self-regulation, appreciation of beauty and perfection, gratitude, hope, humor, and spirituality. It was aimed to examine the learning outcomes in the Life Science Course Curriculum (LSCC) in terms of character strengths in the present study. This research was carried out with the analytical research model. In the research framework, deductive content analysis was used. According to the results, prudence, self-regulation, citizenship, kindness, and social intelligence were the top five character strengths in LSCC. The strengths of bravery, persistence, leadership, forgiveness, modesty, hope, and humor were not found in LSCC. The most prominent virtue in LSCC was temperance. It is noteworthy that courage was the least emphasized virtue in LSCC. As the grade increased, the virtue of wisdom was more emphasized within LSCC learning outcomes. Considering the units, self-regulation, social intelligence, citizenship, kindness, prudence, and open-mindedness were the most emphasized character strengths in the unit of Life in Our School. Self-regulation, prudence, social intelligence, open-mindedness, love, and appreciation were the most common ones in the unit of Life in Our Home. Prudence and selfregulation came to the fore in the units of Healthy Life and the Safe Life. Citizenship in the unit of Life in Our Country and curiosity, love of learning, and love in the unit of Life in Nature became distinctive.

\section{Introduction}

Character is defined as some psychological characteristics that affect individuals' ability to behave morally and shape their disposition in this regard (Berkowitz, 2002). Strong character

\footnotetext{
${ }^{1}$ This study was presented as an oral presentation at the International Pegem Conference on Education held between 16-19 September 2020 .

* Correspondency: ferat.yilmaz@ dicle.edu.tr
} 
development requires the acquisition of some social, emotional, and cognitive skills such as distinguishing right from wrong, identifying the perspectives of others, gaining social standards, exhibiting pro-social behaviors, and getting and using the knowledge required by a sense of well-being (Shoshani, 2019). According to Lickona (1999), a strong character contains various virtues. Virtues refer to fundamental characteristics common to all religious and philosophical approaches, accepted as universal and independent of a particular historical moment (García Castro, Alba, \& Blanca, 2020).

Character encompasses six basic virtues. These virtues can be listed as wisdom, courage, humanity, justice, temperance, and transcendence (Park \& Peterson, 2009). Wisdom is a cognitive virtue that requires the acquisition and use of knowledge, while courage is an emotional virtue associated with using willpower to achieve goals in the face of external or internal opposition. Humanity is recognized as an interpersonal virtue that requires good relationships with others. Justice expresses the virtue related to citizenship that underlies healthy community life. Temperance as a virtue assumes a protective function against extremism. The virtue of transcendence makes it easier to go beyond the current universe and to understand the meaning of life (Peterson \& Park, 2004).

Each virtue comprises various character strengths. Character strengths are positive traits that emerge through thinking, emotion, will, and action and accepted everywhere (García Castro et al., 2020). These strengths can be defined as objective and observable behavioral tendencies embedded in virtues (Crossan, Mazutis, \& Seijts, 2013). In other words, character strengths can be considered as concrete operational indicators of abstract virtues, in daily life. In this context, according to the classification made by Peterson and Seligman (2004), the virtue of wisdom is displayed with the character strengths of creativity, curiosity, open-mindedness, love of learning, and perspective. Courage is manifested by honesty, bravery, perseverance, and zest. Humanity is revealed by kindness, love, and social intelligence whereas justice takes action with fairness, leadership, and citizenship. Temperance, on the other hand, turns into behavior with forgiveness, modesty, prudence, and self-regulation. Lastly, transcendence is reflected in life in the form of appreciation (of beauty and perfection), gratitude, hope, humor, and spirituality.

There are some criteria for a quality to be considered as a character strength. These are characteristics such as acceptance at the intercultural level, contribution to life satisfaction, elevating others, stability, measurability, distinctiveness, selective absence, and embodiment in some people. Besides the above, a character strength is the deliberate target of social practices and institutions, morally valued, exemplary, precociously exhibited by some people, and has obvious antonyms that are "negative" (Park, Peterson, \& Seligman, 2004).

To better understand character strengths, it is important to examine various traits related to them. In this framework, it should be noted that character strengths are derived from the study of religious and philosophical traditions but conceptualized by using the language and methods of contemporary psychology (Baer, 2015). Character strengths are used to show that the character has a multi-dimensional structure (Park \& Peterson, 2009). Character strengths corresponding to each of these dimensions are supportive of each other (Davidson, Lickona, \& Khmelkov, 2008) and are not necessarily considered fixed or invariant biogenetic traits, although they are individual differences with a certain degree of stability and generality (Martínez-Martí \& Ruch, 2017). In fact, it is argued that character strengths are influenced by social and other contextual factors. Therefore, it is thought that they can be shaped, taught, and 
gained through practice (Gillham et al., 2011) and should be used at the virtuous mean level, not excessively or incompletely (Crossan et al., 2013).

As has been mentioned earlier character strengths are influenced by social and other contextual factors. The most important of these factors can be listed as family, society, and education (Gillham et al., 2011; Rashid et al., 2013). In particular, education is seen as an important field for individuals to gain character strengths necessary for them to adapt to developments in the world of the $21^{\text {st }}$ century and to contribute to the global society of the $21^{\text {st }}$ century (Lavy, 2020). Including practices based on character strengths in schools indeed increases life satisfaction and well-being among students (Proctor et al., 2011). With these practices, improvement can also be observed in students in terms of school-related success (Wagner \& Ruch, 2015), general and academic self-esteem (Cuomo, 2020), and positive feelings about school (Weber, Wagner, \& Ruch, 2016).

To gain the character strengths that contribute to the psychological and academic characteristics of the individual scientifically, education programs and curriculums on this subject should be implemented (Kabakci, 2016). However, it is seen that there is no explicit approach for students to gain character strengths in curriculums in Turkey. In addition to this, there is no study on whether these curriculums implicitly contain character strengths. In the Turkish literature, the only document examined in terms of character strengths is the 100 fundamental literary works recommended for primary and secondary school students (Isik, Kilic, Uzbe Atalay, Terzi Ilhan, $\&$ Kaynak, 2019). Since it is uncertain whether the 100 fundamental literary works will be read by all children, it is thought that examining the curriculums delivered to all children in terms of character strengths may contribute to the literature.

Considering that character strengths emerge as individual differences at an early age (Shoshani, 2019), the Life Science Course Curriculum (LSCC), one of the curriculums that children encounter at an early age, is important. To understand whether LSCC has the potential to scientifically contribute to the development of children's character strengths and the virtues expressed by these strengths, learning outcomes in LSCC (Ministry of National Education [MoNE], 2018) should be analyzed in terms of character strengths. Therefore, it was aimed to examine the learning outcomes in LSCC in terms of character strengths in the present study. For this purpose, answers to the following questions were sought:

(1) How is the general distribution of character strengths in LSCC?

(2) How is the distribution of character strengths in LSCC according to grades?

(3) How is the distribution of character strengths in LSCC according to units?

\section{Method}

This research was carried out with the analytical research model. According to the analytical research model, records, media, or documents are analyzed according to themes such as various concepts, events, facts, situations, and thoughts. Although this research model cannot be fully classified as quantitative or qualitative, it has a certain level of quantitative and qualitative characteristics (McMillan, 2004; cited in Ersoy, 2015). In this context, LSCC was examined in terms of character strengths in the present study. While the use of document analysis illustrates that the research has qualitative features, it can be said that there are also quantitative features in the research due to the digitization of the obtained data.

In the present research, LSCC (MoNE, 2018) published on the website of the Board of 
Education was examined as a document. The research data consisted of 148 learning outcomes (and explanations about these learning outcomes, if any) included in the Life in Our School (LOSU), Life in Our Home (LOHU), Healthy Life (HLU), Safe Life (SLU), Life in Our Country (LOCU), and Life in Nature (LNU) units for the $1^{\text {st }}, 2^{\text {nd }}$ and $3^{\text {rd }}$ grades of this document. The learning outcomes in the program were not subjected to any criteria for inclusion in the study, a sample selection was not made, and all learning outcomes were examined in this regard.

In the current research framework, deductive content analysis was used. In this context, the virtues included in the VIA (Values in Action) classification made by Peterson and Seligman (2004) were accepted as themes. The character strengths under these virtues were considered as categories and the extent to which LSCC contains these categories and themes was examined. During this review, the preparation, organizing, and reporting phases recommended by Elo and Kyngäs (2008) were followed. In the preparation phase, it was decided to examine LSCC at first. However, since LSCC has many elements such as textbooks, materials, in-class practices, homework, and out-of-school activities, the learning outcomes that guide all of these elements were chosen as the unit of analysis. It was decided to reveal not only the manifest contents (categories) but also the latent contents (themes) of these learning outcomes. All learning outcomes were read repeatedly to make sense of each as well as all of the learning outcomes. In the organizing phase, an analysis matrix was created first. While virtues, the themes of the research, were placed on the vertical dimension of this analysis matrix, the categories of the research, character strengths, were placed on the horizontal dimension. Later, the learning outcomes in the $1^{\text {st }}, 2^{\text {nd }}$, and $3^{\text {rd }}$ grades of LSCC were coded in terms of categories and placed in appropriate cells. In the phase of reporting the analysis process and the result, the values obtained from the analysis matrices were digitized in frequencies and presented in tables. Since character strengths are interrelated (Brdar \& Kashdan, 2010), some learning outcomes were associated with more than one category (viz. character strength) at the same time. However, the learning outcomes associated with more than one character strength under the same theme (virtue) were counted only once when expressing frequencies for themes. For example, the learning outcome of "Participate in the process of determining in-class rules." was evaluated within the creativity category because it requires generating many different ideas on this subject. Besides, the learning outcome was evaluated under the category of open-mindedness, as it requires considering other ideas about what the classroom rules should be, and it was also considered in the perspective category, as it includes providing a perspective to others on this issue. Therefore, while the learning outcome was counted three times separately under three separate categories, it was included in the count only once under the theme of the virtue of wisdom to which these three categories are related.

To ensure the validation of the research, sufficient participation was provided, the external audits technique was applied, and triangulation among analysts was made. In the framework of reliability, the audit trail technique was used (Creswell, 2007; Merriam, 2015; Patton, 2014) and the reliability coefficient between coders was calculated. All learning outcomes in LSCC have been included in the research to ensure sufficient participation.

Within the scope of external audits, research data and coding were shared with an academician who was not related to the research and has a doctorate in the field of Education Programs and Instruction. The academician (external auditor) was asked to examine whether the findings, comments, and conclusions were based on the data. The external auditor criticized the result of "While the most emphasized virtue in LSCC learning outcomes is temperance, the least emphasized virtue is courage. Therefore, it can be said that LSCC aims to raise children who are temperate but not brave." under the title of conclusion and discussion and stated that the 
character strengths of bravery and the virtue of courage were mixed in this statement of the result. In addition, the external auditor mentioned that although the strength of bravery was never encountered, the virtue of courage was encountered when the data and findings were examined. Based on this criticism, in the relevant part of the conclusion and discussion, it was explained that the character strength of bravery under the virtue of courage was never addressed; thus, the aforementioned result was grounded. Apart from this, it was stated that the results and discussions were finalized within the limits of "learning outcomes" with the suggestion of the external auditor. The learning outcomes in LSCC were analyzed by two different analysts using the technique of triangulation among these analysts. While one of the analysts was the conductor of the current research, the other was an academic who has a doctorate in the field of primary education. It was tried to explain how the categories obtained from the research were reached within the framework of the audit trail technique. To create the categories correctly, all the references cited in the introduction and discussion part of the research were examined, first. In this way, different equivalents/nomenclatures of character strengths and virtues were determined (e.g., self-control, self-regulation). Different definitions of virtue and character strengths were brought together, and all definitions obtained from the literature were taken into account to place a learning outcome in the relevant theme and category. Furthermore, the nuances between character strengths (like prudence and selfregulation) that are under the same virtue and may contain similar meanings were determined. Finally, to assure a faster and more accurate coding, keywords related to the categories were created such as social responsibility, cooperation, commitment, and alike for citizenship. Thus, when there was uncertainty about the category under which a learning outcome fell, these procedures facilitated decisions that are more reliable. Sample learning outcomes related to the themes and categories are presented in Table 1:

Table 1. Sample coding, theme, and categories

\begin{tabular}{ll}
\hline Virtues and character strengths & Sample learning outcome (Students will be able to...) \\
\hline WISDOM & $\begin{array}{l}\text { HB.3.1.9. Make original suggestions for the effective and efficient use } \\
\text { of school resources. }\end{array}$ \\
Curiosity & $\begin{array}{l}\text { HB.1.6.7. Research the seasons and their characteristics. } \\
\text { HB.2.5.7. Respect the lifestyles and habits of people in different cultures } \\
\text { living in our country. }\end{array}$ \\
Loven of learning & HB.1.1.16. Develop positive feelings and thoughts about the school. \\
Perspective & HB.2.5. Take part in decision-making processes in the family.
\end{tabular}

HB.2.1.1. Introduce themselves with their unique features. (Physical characteristics, likes, skills, and goals are emphasized)

Honesty

Zest

HUMANITY

Kindness

HB.3.5.7. Participate in social responsibility projects aimed at addressing the problems of people of different cultures living in our country.

Love HB.3.1.4. Understand the issues to be considered in the friendship process.

Social intelligence

HB.3.1.2. Realize how their behaviors affect them and their friends. JUSTICE

Fairness

Citizenship

TEMPERANCE
HB.3.2.4. Fulfill their duties and responsibilities at home.

HB.1.5.3. Recognize the general characteristics of our country. 


\begin{tabular}{ll}
\hline Virtues and character strengths & Sample learning outcome (Students will be able to...) \\
\hline $\begin{array}{l}\text { Prudence } \\
\text { Self-regulation }\end{array}$ & HB.1.4.7. Distinguish safe and unsafe areas for themselves. \\
TRANSCENDENCE & HB.2.3.2. Prepare a meal list suitable for a balanced diet. \\
Appreciation & $\begin{array}{l}\text { HB.3.2.5. Give examples of the contribution of household appliances } \\
\text { and technological products to our lives. }\end{array}$ \\
Gratitude & $\begin{array}{l}\text { HB.1.3.6. Obey the etiquette while eating. (While eating at school, the } \\
\text { issue of starting the meal with prayer is emphasized) }\end{array}$ \\
Spirituality & HB.2.5.5. Understand the importance of religious days and holidays. \\
None & HB.2.2.3. Know the address of the house where they live. \\
\hline
\end{tabular}

To comment on reliability apart from the audit trail technique, the consistency between coders was calculated by using the formula "agreement / (agreement + disagreement)". To carry out this process, the coding by two different analysts within the scope of analyst triangulation was taken into account. In cases where there was a disagreement between the two analysts, the opinion of a third analyst who has a Ph.D. degree in the field of curriculum and instruction was consulted. Although such a case was accepted as a disagreement, the related learning outcome was placed in the category that two of the three analysts found appropriate. As a result, the reliability rate between analysts was determined as $89 \%$. Since this rate was over $70 \%$ (Miles \& Huberman, 1994), it was concluded that the coding was mostly reliable.

\section{Findings}

\section{Findings regarding the general distribution of character strengths in LSCC}

The findings regarding the distribution of character strengths in LSCC learning outcomes, in general, are provided in Figure 1.

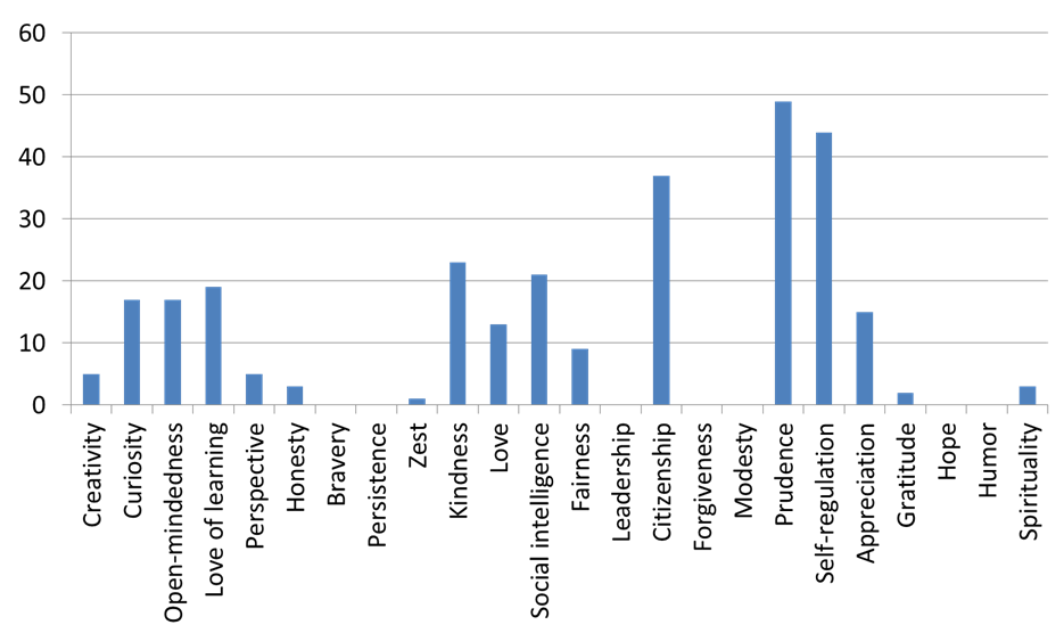

Figure 1. Character strengths in LSCC learning outcomes

According to Figure 1, prudence, self-regulation, citizenship, kindness, and social intelligence were the top five character strengths in LSCC. The strengths of bravery, persistence, leadership, forgiveness, modesty, hope, and humor were not found in LSCC.

Findings on how virtues reveal a general distribution within LSCC learning outcomes are 
demonstrated in Figure 2.

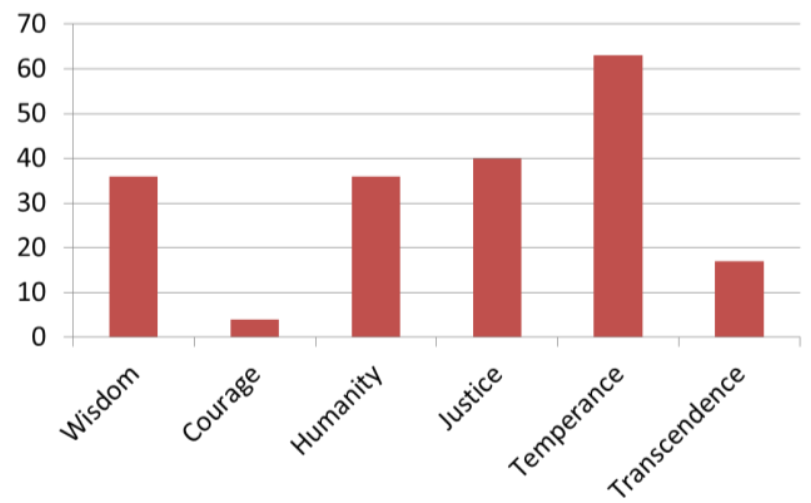

Figure 2. The virtues involved in LSCC learning outcomes

According to Figure 2, the most prominent virtue in LSCC was temperance ( $f=63$ ). This virtue was followed by justice $(f=40)$, wisdom $(f=36)$, humanity $(f=36)$, and transcendence $(f=$ $17)$, respectively. It is noteworthy that courage was the least emphasized $(f=4)$ virtue in LSCC.

\section{Findings regarding the distribution of character strengths in LSCC according to grades}

Findings regarding the distribution of character strengths within LSCC learning outcomes in terms of grades are presented in Table 2.

Table 2. Distribution of character strengths in LSCC according to grades

\begin{tabular}{llll}
\hline Virtues and character strengths & $\mathbf{1}^{\text {st }} \mathbf{G r a d e}$ & $\mathbf{2}^{\text {nd }}$ Grade & $\mathbf{3}^{\text {rd }}$ Grade \\
\hline WISDOM & 8 & 12 & 16 \\
\hline Creativity & 1 & 2 & 2 \\
Curiosity & 4 & 6 & 7 \\
Open-mindedness & 3 & 7 & 7 \\
Love of learning & 5 & 6 & 8 \\
Perspective & 1 & 2 & 2 \\
\hline COURAGE & 2 & 2 & 0 \\
\hline Honesty & 1 & 2 & \\
Bravery & & & \\
Persistence & & & 12 \\
Zest & 1 & 12 & 6 \\
\hline HUMANITY & 12 & 8 & 4 \\
\hline Kindness & 9 & 4 & 4 \\
Love & 5 & 10 & 12 \\
Social intelligence & 7 & 12 & 3 \\
\hline JUSTICE & 16 & 3 & 11 \\
\hline Fairness & 3 & & 16 \\
Leadership & & 10 & \\
Citizenship & 16 & 23 & \\
\hline TEMPERANCE & 24 & & \\
\hline & & & \\
\hline
\end{tabular}




\begin{tabular}{llll}
\hline Virtues and character strengths & $\mathbf{1}^{\text {st }}$ Grade & $\mathbf{2}^{\text {nd }}$ Grade & $\mathbf{3}^{\text {rd }}$ Grade \\
\hline Forgiveness & & & \\
Modesty & 18 & 16 & 15 \\
Prudence & 18 & 19 & 7 \\
$\quad$ Self-regulation & 4 & 5 & 8 \\
\hline TRANSCENDENCE & 2 & 5 & 8 \\
\hline Appreciation & 1 & & 1 \\
Gratitude & & & \\
Hope & & 1 & 3 \\
Humor & 2 & 10 & \\
Spirituality & 6 & & \\
\hline None & & & \\
\hline
\end{tabular}

When Table 2 was evaluated, it was understood that as the grade increased, the virtue of wisdom was more emphasized within LSCC learning outcomes. The virtue of courage did not prevail at any grade. The virtue of humanity had the same frequency at all grades. While the virtue of justice was emphasized relatively more in the $1^{\text {st }}$ grade, it had the same frequency in the $2^{\text {nd }}$ and $3^{\text {rd }}$ grades. The virtue of temperance was one of the most emphasized virtues in every grade. Transcendence was more common in the 3 rd grade.

The most emphasized five character strengths in $1^{\text {st }}$ and $2^{\text {nd }}$ grades were prudence, selfregulation, citizenship, social intelligence, and kindness. In the $3^{\text {rd }}$ grade, prudence, citizenship, and self-regulation were among the first five character strengths. Additionally, character strengths of appreciation, love of learning, curiosity, and open-mindedness were also in the top five in terms of their frequencies. Honesty and spirituality character strengths were given a little place in the $1^{\text {st }}$ and $2^{\text {nd }}$ grades, but not in the $3^{\text {rd }}$ grade. Gratitude, on the other hand, took little place in the $1^{\text {st }}$ and $3^{\text {rd }}$ grades, but never in the $2^{\text {nd }}$ grade.

\section{Findings Regarding the Distribution of Character Strengths in LSCC According to Units}

When LSCC units are examined in terms of character strength, the findings in Table 3 are encountered.

Table 3. Distribution of character strengths in LSCC according to units

\begin{tabular}{lllllll}
\hline Virtues and character strengths & LOSU & LOHU & HLU & SLU & LOCU & LNU \\
\hline WISDOM & 10 & 7 & 2 & 0 & 9 & 8 \\
\hline Creativity & 3 & 2 & & & & \\
Curiosity & 1 & 2 & & & 8 & 6 \\
Open-mindedness & 7 & 4 & 2 & & 2 & 2 \\
Love of learning & 3 & 2 & & & 8 & 6 \\
$\quad$ Perspective & 3 & 2 & & & & \\
\hline COURAGE & 2 & 2 & 0 & 0 & 0 & 0 \\
\hline Honesty & 1 & 2 & & & & \\
Bravery & & & & & & \\
Persistence & & & & & & \\
Zest & 1 & & & &
\end{tabular}




\begin{tabular}{lllllll}
\hline Virtues and character strengths & LOSU & LOHU & HLU & SLU & LOCU & LNU \\
\hline HUMANITY & 18 & 5 & 3 & 1 & 4 & 5 \\
\hline Kindness & 10 & 2 & 3 & 1 & 4 & 3 \\
Love & 3 & 4 & & 1 & & 5 \\
Social intelligence & 13 & 5 & & 1 & 2 & \\
\hline JUSTICE & 13 & 4 & 1 & 1 & 19 & 2 \\
\hline Fairness & 3 & 1 & 1 & & 3 & 1 \\
Leadership & & & & & & \\
Citizenship & 11 & 4 & & 1 & 19 & 2 \\
\hline TEMPERANCE & 15 & 10 & 18 & 17 & 0 & 3 \\
\hline Forgiveness & & & & & & \\
Modesty & & & & & & 3 \\
Prudence & 7 & 6 & 16 & 17 & & 2 \\
$\quad$ Self-regulation & 13 & 8 & 15 & 8 & & \\
\hline TRANSCENDENCE & 1 & 4 & 1 & 0 & 9 & \\
\hline $\begin{array}{l}\text { Appreciation } \\
\text { Gratitude }\end{array}$ & 1 & 4 & & & 8 & 2 \\
Hope & & & 1 & & 1 & \\
Humor & & & & & & \\
Spirituality & & & 1 & & 2 & \\
\hline None & 5 & 3 & 1 & 1 & 2 & \\
\hline & & & & & & \\
\hline
\end{tabular}

According to Table 3, when examined in terms of units, the most emphasized virtues were humanity in LOSU, temperance in LOHU, HLU, and SLU, justice in LOCU, and wisdom in LNU. In terms of character strengths, self-regulation, social intelligence, citizenship, kindness, prudence, and open-mindedness were the most emphasized in LOSU. Self-regulation, prudence, social intelligence, open-mindedness, love, and appreciation were the most common ones in LOHU. Prudence and self-regulation came to the fore in HLU and SLU. In LOCU and LNU, unlike the others, self-regulation and prudence were either not emphasized at all or less emphasized than other character strengths. Citizenship in LOCU, curiosity, love of learning, and love character strengths in LNU became distinctive.

\section{Results and Discussion}

While the most emphasized virtue in LSCC learning outcomes was temperance, the least emphasized virtue was courage. Under the virtue of courage, the character strength of bravery was never mentioned. For this reason, it can be said that LSCC aims to raise children who are temperate but not brave. Temperance, the most emphasized virtue in LSCC, appeared as the least emphasized virtue in the 100 fundamental literary works suggested for primary school students (Isik et al., 2019). In this sense, it is thought that LSCC and 100 fundamental literary works may balance each other in terms of the virtue of temperance.

Considering the studies that examine the variables in which temperance had a correlational relationship, the possible effects of LSCC regarding the virtue of temperance can be interpreted. Accordingly, by emphasizing the virtue of temperance, LSCC may help students avoid experiences (being hurt, excessive tolerance, addiction) that reduce their well-being (Gillham et al., 2011) and contribute to their mental health (Shoshani, 2019). However, the fact that this 
virtue was emphasized 50\% more than justice, the second most emphasized virtue, may have some negative effects. Accordingly, overly moderate students may become easily deceived, self-denigrating, overly cautious, and rigid individuals (Crossan et al., 2013). Such individuals may lack the assertiveness, entrepreneurship, self-confidence and flexibility that the new world order requires.

Less emphasis on the virtue of courage in LSCC than other virtues may have some negative consequences. If students cannot develop this virtue from different sources in a healthy way, they may become individuals who give up in the face of difficulties, may not defend the truth in the face of opposing views, and may act as expected rather than as they believe (Park et al., 2004). Students deprived of courage may not contribute to social functioning (Biswas-Diener, 2006). In addition, these students' level of engagement with life may decrease (Wagner, Gander, Proyer, \& Ruch, 2020). As a result, the number of citizens with undesirable moral, social, and psychological qualities may increase.

The five character strengths that people emphasize the most in terms of their identity are known as signature strengths. Signature strengths can naturally affect daily behavior (Macfarlane, 2019). It is possible that the five character strengths, which are the most in LSCC that aims to change behavior through teaching, will affect the signature strengths of the students. Then, the five most common character strengths in LSCC become important. According to the current study, these character strengths included prudence, self-regulation, citizenship, kindness, and social intelligence.

While prudence, a character strength related to the virtue of temperance, was the least common character strength among people in American culture (Park, Peterson, \& Seligman, 2006), it was observed as the most mentioned character strength in LSCC that has an acculturation function. This may mean that the features of Turkish society such as prudent child-rearing and prudent economic activities are reinforced by curriculums. Considering the other variables related to prudence, it is thought that this situation may contribute to the life satisfaction of students (Abasimi, Gai, \& Wang, 2017). While self-regulation, another character strength related to the virtue of temperance, were identified as one of the least possessed character strengths among people living in 75 different countries (McGrath, 2015), it drew attention as the second most common character strength in LSCC. Since this character strength is related to success (Lounsbury, Fisher, Levy, \& Welsh, 2009; Wagner et al., 2020), positive class behavior (Wagner \& Ruch, 2015), and sustainable behavior (Corral-Verdugo, Tapia-Fonllem, \& OrtizValdez, 2015), it is important that it is frequently included in LSCC. However, it should be remembered that excessive prudence leads to conservatism and excessive self-regulation leads to the restriction (Freidlin, Littman-Ovadia, \& Niemiec, 2017). Because in the global, capitalist, and competitive world, excessive prudence may cause us to fall behind countries of less prudent citizens like the United States of America.

The fact that citizenship (teamwork), which is the behavioral indicator of the virtue of justice, was among the most emphasized character strengths in LSCC is considered as a positive situation in terms of children's mental health (Shoshani, 2019), regarding peer status indicators such as peer acceptance and the number of friends (Wagner, 2019), alongside achievements (Weber \& Ruch, 2012). This situation also shows that LSCC can successfully fulfill its role in raising effective citizens. One of the most emphasized character strengths in LSCC was kindness, which people from many different cultures thought they had the most (McGrath, 2015). Considering the literature, it can be said that the inclusion of kindness in LSCC may help people to establish positive (Wagner et al., 2020) and harmonious (Littman-Ovadia \& 
Lavy, 2012) relationships with their environment. A positive school and classroom climate may be created as kindness may help others be kind too (Niemiec, 2020). Besides, since kindness is associated with service-orientation which is one of the $21^{\text {st }}$ century skills (Lavy, 2020) students who have been trained to be kind may have a sense of social responsibility. Like kindness, social intelligence, which is a character strength related to humanity virtue, was emphasized more than many other character strengths in LSCC. Since social intelligence was positively related to achievement (Wagner et al., 2020) and positive feelings about school (Weber et al., 2016) and negatively related to negative life experiences (García-Castro et al., 2020) and social anxiety (Freidlin et al., 2017), this situation can be considered as a positive feature of LSCC. All these findings can be interpreted as LSCC can serve to educate students who have some positive character strengths in terms of social relations.

As a result of this research, it was understood that the strengths of bravery, persistence, leadership, forgiveness, modesty, hope, and humor were not included in LSCC. If these character strengths are not emphasized at all or are not sufficiently developed in students, undesirable features such as cowardice, vulnerability, adaptation to every situation, ruthlessness, baseless self-esteem, pessimism, and extreme seriousness may be observed (Freidlin et al., 2017). The absence of these character strengths other than modesty may make it difficult to experience a sense of well-being (Aydin, 2017; Hausler et al., 2017; Kabakci, 2013; Shoshani, 2019; Wagner et al., 2020) or success (Aydin, 2017; Kabakci, 2013; Weber et al., 2016). Lack of hope, persistence, and humor may reduce life satisfaction in different areas (Abasimi et al., 2017; Buschor, Proyer, \& Ruch, 2013; Weber \& Ruch, 2012). That said, not having the character strengths of bravery and hope may negatively affect resilience (MartínezMartí \& Ruch, 2017) whilst not being persistent and not having the strength of humor may decrease the student satisfaction (Lounsbury et al., 2009). Apart from these, even if students who have not developed the strength of bravery make moral decisions, they may not be able to turn these decisions into moral actions (Han, 2019). They may not be able to develop $21^{\text {st }}$ century skills such as assertiveness, communication, self-expression, and social interaction (Lavy, 2020) either. People who lack leadership skills may have problems in terms of job satisfaction (Heintz \& Ruch, 2020) and engagement (Wagner et al., 2020). People who do not have the character strength of hope that did not exist in LSCC, on the other hand, may not reach the desired level in terms of positive self-evaluation (Lavy, 2020) or academic self-efficacy (Weber \& Ruch, 2012). Finally, people without the character strength of humor may experience some problems in terms of social anxiety (Freidlin et al., 2017) and as to coping strategies (Harzer \& Ruch, 2015).

Other character strengths not included in LSCC were forgiveness and modesty. Since these character strengths require certain cognitive maturity (Park \& Peterson, 2006a) it may be understandable why they were not included in LSCC. However, due to the positive relationship between them (Corral-Verdugo et al., 2015), it is predicted that people who are not modest or forgiving may be less likely to display sustainable behaviors. Accordingly, students who cannot grow up in a modest or forgiving manner may not exhibit environmentally sustainable behaviors aimed at LSCC. Individuals who are not forgiving or modest may not be successful in conflict resolution processes and may be disappointed in many areas of life.

Modesty did not have a positive relationship with the variables of well-being (Wagner et al., 2020; Shoshani, 201), life satisfaction (Azañedoa, Fernández-Abascal, \& Barraca, 2014), selforiented emotions such as joy, satisfaction, and pride (Güsewell \& Ruch, 2012), or success (Lounsbury et al., 2009). This situation demonstrates that not including modesty in LSCC may not pose major problems in terms of the aforementioned variables. However, considering that 
these variables are mostly related to the very individual, it is thought that this situation may not eliminate the importance of modesty in terms of social relations.

According to the results of this research, the virtues of wisdom and transcendence were emphasized more within LSCC learning outcomes as the grade level increased. Considering that wisdom (Azañedoa et al., 2014) and transcendence (Leontopoulou \& Triliva, 2012) were virtues that revealed positive correlations with the age variable, it may be an appropriate approach to include these virtues more in LSCC with advancing grade levels. The fact that the virtues of humanity and justice were included in certain proportions at all grades and generally among LSCC learning outcomes illustrates that others-oriented virtues are valued at every grade level. The five most emphasized character strengths for the $1^{\text {st }}$ and $2^{\text {nd }}$ grades were prudence, self-regulation, citizenship, social intelligence, and kindness. These character strengths are necessary and appropriate, especially for students who have not received preschool education and will be socialized for the first time in formal education institutions in order to protect themselves in social life and to be sensitive to others. At the $3^{\text {rd }}$ grade, prudence, citizenship, and self-regulation were among the first five character strengths. However, character strengths of appreciation, love of learning, curiosity, and open-mindedness were also in the top five in terms of their frequencies. Since these four character strengths are indicators of virtues of wisdom and transcendence associated with age and require cognitive maturity (Park \& Peterson, 2006b), it is argued that it may be reasonable for them to be in the $3^{\text {rd }}$ grade. Honesty and spirituality were given a small emphasis at the $1^{\text {st }}$ and $2^{\text {nd }}$ grade levels, but not at the $3^{\text {rd }}$ grade. Gratitude took place little at the $1^{\text {st }}$ and $3^{\text {rd }}$ grades, but never at the $2^{\text {nd }}$ grade. When the lack of honesty is evaluated in terms of its relationships with friendship (Wagner, 2019) and responsibility (Littman-Ovadia \& Lavy, 2012), this situation may be accepted as an aspect of LSCC that needs improvement. However, the scarcity of the strengths of transcendence such as spirituality and gratitude cannot be presented as an aspect of LSCC that can be criticized negatively since it is more appropriate to deal with these strengths as part of courses such as "culture of religion and knowledge of ethics" taught from $4^{\text {th }}$ grade, instead of LSCC.

When examined in terms of units, the virtue of humanity was mostly emphasized in LOSU and this virtue was supported by the character strengths of the virtue of temperance. This situation is valuable in that it may make it easier for students to grow up as individuals who are humane and temperate in terms of other people in their school life and create a positive school climate. The fact that temperance was the most emphasized virtue in LOHU may help children to regulate their behavior at home. Besides, the prominence of character strengths related to humanity such as social intelligence and love in LOHU may improve the social structure of the family, the smallest social institution. The open-mindedness emphasized in this unit may contribute to the democratic structure of the family, and the strength of appreciation may pave the way for students to appreciate their families.

In HLU and SLU the virtue of temperance and the character strengths of this virtue, prudence and self-regulation, came into prominence. This situation reveals that the units are compatible with the virtues and character strengths they contain. Because a healthy and safe life requires students to be prudent in their social lives, technological environments, nutritional habits, and even in dressing choices, to regulate their wishes and needs, and to control their desires and habits. So and so, the study conducted by Proyer, Gander, Wellenzohn, and Ruch (2013) revealed that prudence and self-regulation were associated with healthy eating. 
In LOCU, the virtue of justice and the character strength of citizenship were highly regarded. It is known that these strengths are important for raising citizens who fulfill their individual responsibilities within the framework of a fair life in their country. However, it is noteworthy that the virtue of humanity, which is as necessary as justice to live happily in a country, was not emphasized enough in LSCC, especially in terms of love. However, positive human relations must be guaranteed not only by the written norms required by justice but also by the unwritten norms required by humanity. It is thought that a loving society and country can be built in this way.

In LNU curiosity and love of learning related to the virtue of wisdom and love related to the virtue of humanity became distinctive. Including the strengths of wisdom such as curiosity and love of learning in LNU can be considered as a positive situation especially in terms of being able to prepare students for scientific process skills for the science course. Besides, these intellectual strengths may make it easier for students to participate in the (ecological) environment they live in (Gillham et al., 2011). The inclusion of love in LNU as a character strength associated with environmentally sustainable behaviors (Corral-Verdugo et al., 2015) may represent a logical approach for students to exhibit sustainable behaviors related to nature. In addition, love may remind students that they are not the only beings living in nature and that they should humanely approach other beings. However, considering the human greed and harmful behaviors against nature, the lack of self-regulation character strength, which can be important to control the ambition and behaviors, can be criticized for the development of LSCC.

\section{Limitations}

This research is limited to LSCC. Thereupon, the comments made, the results obtained, and the discussions made do not reflect other primary school programs. Within the scope of the research, only the learning outcomes and the explanations of the gains, if any, were examined. Therefore, the information and findings revealed by the research are not related to the core values, competencies, or skills in LSCC.

\section{Suggestions}

- In LSCC, the virtue of courage and the character strengths of honesty and persistence should be given more space in this context.

- Psychological counseling and guidance should be provided to students so that excessive use of the virtue of temperance does not turn students into rigid, conservative, and restricted people.

- The character strength of leadership should be emphasized in LSCC.

- To consolidate the character strength of hope in children, they should be encouraged to make optimistic predictions about the future of their schools, homes, nature, and their country.

- The character strengths of gratitude and spirituality, which LSCC does not contain much, should be brought to the forefront in courses such as the culture of religion and knowledge of ethics starting from the 4th grade or in the philosophy course at higher levels. Character strengths such as modesty and forgiveness should also be brought to the forefront in courses such as Turkish and social studies from the 4th grade, along with the culture of religion and knowledge of ethics course.

- Teachers should make use of humorous elements while teaching the course of life science to develop the character strength of humor of their students. 
- Teachers should carry out activities related to courage based on the skill of decisionmaking (standing behind their decisions) and the core value of honesty that LSCC aims to develop.

- The virtue of humanity, as the virtue of justice, should be voiced more frequently in LOCU.

- The character strength of self-regulation should be emphasized more in LNU. In this way, human beings should be made to review their unconcerned greed and excessively selfish behaviors in nature.

- Students should be supported by their families in terms of character strengths not included in LSCC. When necessary, families should also be educated about character strengths.

\section{References}

Abasimi, E., Gai, X., \& Wang, G. (2017). Character strengths and life satisfaction of high school students. International Journal of Applied Psychology, 7(2), 36-43. doi: 10.5923/j.ijap.20170702.02

Aydin, F. T. (2017). Forgiveness as a positive character strength. The Journal of Happiness \& Well-Being, 5(1), 1-22.

Azañedoa, C. M., Fernández-Abascal, E. G., \& Barraca, J. (2014). Character strengths in Spain: Validation of the Values in Action Inventory of Strengths (VIA-IS) in a Spanish sample. Clínica y Salud, 25, 123-130.

Baer, R. (2015). Ethics, values, virtues, and character strengths in mindfulness-based interventions: A psychological science perspective. Mindfulness, 6, 956-959. doi: $10.1007 / \mathrm{s} 12671-015-0419-2$

Berkowitz, M. W. (2002). The science of character education. In W. Damon (Ed.), Bringing in a new era in character education (pp. 43-63). Stanford, CA: Hoover Institution Press.

Biswas-Diener, R. (2006). From the Equator to the North Pole: A study of character strengths. Journal of Happiness Studies, 7, 293-310. doi:10.1007/s10902-005-3646-8

Brdar, I., \& Kashdan, T. B. (2010). Character strengths and well-being in Croatia: An empirical investigation of structure and correlates. Journal of Research in Personality, 44, 151154. doi: 10.1016/j.jrp.2009.12.001

Buschor, C., Proyer, R. T., \& Ruch, W. (2013). Self- and peer-rated character strengths: How do they relate to satisfaction with life and orientations to happiness? The Journal of Positive Psychology, 8(2), 116-127. doi: 10.1080/17439760.2012.758305

Corral-Verdugo, V., Tapia-Fonllem, C., \& Ortiz-Valdez, A. (2015). On the relationship between character strengths and sustainable behavior. Environment and Behavior, 47(8), 877-901. doi: 10.1177/0013916514530718

Crossan, M., Mazutis, D., \& Seijts, G. (2013). In search of virtue: The role of virtues, values and character strengths in ethical decision making. J Bus Ethics, 113, 567-581. doi:10.1007/s10551-013-1680-8

Davidson, M., Lickona, T., \& Khmelkov, V. (2008). Smart \& good schools: A new paradigm for high schools character education. In L. P. Nucci, \& D. Narvaez (Eds.), Handbook of moral and character education (pp. 370-390). New York, NY: Routledge.

Elo, S., \& Kyngäs, H. (2008). The qualitative content analysis process. Journal of advanced nursing, 62(1), 107-115. doi: 10.1111/j.1365-2648.2007.04569.x

Ersoy, A. (2015). Investigation of PhD students' initial qualitative research experiences via their diaries. Pegem Journal of Education and Instruction, 5(5), 549-568. doi: 10.14527/pegegog.2015.030 
Freidlin, P., Littman-Ovadia, H., \& Niemiec, R. M. (2017). Positive psychopathology: Social anxiety via character strengths underuse and overuse. Personality and Individual Differences, 108, 50-54. doi: 10.1016/j.paid.2016.12.003

García-Castro, F. J., Alba, A., \& Blanca, M. J. (2020). Association between character strengths and caregiver burden: Hope as a mediator. Journal of Happiness Studies, 21, 14451462. doi:https://doi.org/10.1007/s10902-019-00138-2

Gillham, J., Adams-Deutsch, Z., Werner, J., Reivich, K., Coulter-Heindl, V., Linkins, M., .. . Seligman, M. E. (2011). Character strengths predict subjective well-being during adolescence. The Journal of Positive Psychology, 6(1), 31-44. doi: $10.1080 / 17439760.2010 .536773$

Gusewell, A., \& Ruch, W. (2012). Are only emotional strengths emotional? Character strengths and disposition to positive emotions. Applied Psychology: Health and Well-Being, 4(2), 218-239. doi: 10.1111/j.1758-0854.2012.01070.x

Han, H. (2019). The VIA inventory of strengths, positive youth development, and moral education. The Journal of Positive Psychology, 14(1), 32-40. doi: 10.1080/17439760.2018.1528378

Harzer, C., \& Ruch, W. (2013). The application of signature character strengths and positive experiences at work. J Happiness Stud, 14, 965-983. doi: 10.1007/s10902-012-9364-0

Harzer, C., \& Ruch, W. (2015). The relationships of character strengths with coping, workrelated stress, and job satisfaction. Frontiers in Psychology, 6, 1-12. doi: 10.3389/fpsyg.2015.00165

Hausler, M., Strecker, C., Huber, A., Brenner, M., Hoge, T., \& Hofer, S. (2017). Distinguishing relational aspects of character strengths with subjective and psychological well-being. Frontiers in psychology, 8, 1-12. doi: 10.3389/fpsyg.2017.01159

Heintz, S., \& Ruch, W. (2020). Character strengths and job satisfaction: Differential relationships across occupational groups and adulthood. Applied Research in Quality of Life, 15, 503-527. doi: 10.1007/s11482-018-9691-3

Isik, S., Kilic, S., Uzbe Atalay, N., Terzi Ilhan, S., \& Kaynak, U. (2019). Investigation of character strengths in 100 fundamental literary works recommended to primary and secondary school students. Hacettepe University Journal of Education, 34(3), 839-859. doi: 10.16986/HUJE.2018045432

Kabakci, O. F. (2016). Character strengths and virtues: a new approach to strengths-based counseling and values education. Turkish Psychological Counseling and Guuidance Association, 6(45), 25-40.

Lavy, S. (2020). A review of character strengths interventions in twenty-first-century schools: their Importance and how they can be fostered. Applied Research in Quality of Life, 15, 573-596. doi: 10.1007\%2Fs11482-018-9700-6

Leontopoulou, S., \& Triliva, S. (2012). Explorations of subjective wellbeing and character strengths among a Greek University student sample. International Journal of Wellbeing, 2(3), 251-270. doi: 10.5502/ijw.v2.i3.6

Lickona, T. (1999). Character Education: Seven Crucial Issues. Action in Teacher Education, 20(4), 77-84.

Littman-Ovadia, H., \& Lavy, S. (2012). Character strengths in Israel Hebrew adaptation of the VIA inventory of strengths. European Journal of Psychological Assessment, 28(1), 4150. doi: 10.1027/1015-5759/a000089

Lounsbury, J. W., Fisher, L. A., Levy, J. J., \& Welsh, D. P. (2009). An investigation of character strengths in relation to the academic success of college students. Individual Differences Research, 7(1), 52-69.

Macfarlane, J. (2019). Exploring how awareness of character strengths can benefit mental health nurses. British Journal of Mental Health Nursing, 8(3), 145-152. 
Martínez-Martí, M. L., \& Ruch, W. (2017). Character strengths predict resilience over and above positive affect, self-efficacy, optimism, social support, self-esteem, and life satisfaction. The Journal of Positive Psychology, 12(2), 110-119. doi: 10.1080/17439760.2016.1163403

McGrath, R. E. (2015). Character strengths in 75 nations: An update. The Journal of Positive Psychology, 10(1), 41-52. doi: 10.1080/17439760.2014.888580

Miles, M. B., \& Huberman, A. M. (1994). An expanded sourcebook qualitative data analysis. Thousan Oaks, California: Sage Publications.

Ministry of National Education [MoNE]. (2018). Hayat bilgisi dersi ogretim programi (Ilkokul 1,2 ve 3. siniflar) [Life science course curriculum $\left(1^{\text {st }}, 2^{\text {nd }}\right.$, and $3^{\text {rd }}$ grades]. Retrieved from http://mufredat.meb.gov.tr/ProgramDetay.aspx?PID=326 on January 14, 2020.

Niemiec, R. M. (2020). Six functions of character strengths for thriving at times of adversity and opportunity: A theoretical perspective. Applied Research in Quality of Life, 15, 551572. doi: $10.1007 \% 2$ Fs $11482-018-9692-2$

Park, N. (2004). Character strengths and positive youth development. The Annals of the American Academy of Political and Social Science, 591(1), 40-54.

Park, N., \& Peterson, C. (2006a). Character strengths and happiness among young children: Content analysis of parental descriptions. Journal of Happiness Studies, 7(3), 323-341. doi: 10.1007/s10902-005-3648-6

Park, N., \& Peterson, C. (2006b). Moral competence and character strengths among adolescents: The development and validation of the Values in Action Inventory of Strengths for Youth. Journal of adolescence, 891-909. doi: 10.1016/j.adolescence.2006.04.011

Park, N., \& Peterson, C. (2009). Character strengths: Research and practice. Journal of College \& Character, 10(4), 1-10.

Park, N., Peterson, C., \& Seligman, M. E. (2004). Strengths of character and well-being. Journal of Social and Clinical Psychology, 23(5), 603-619.

Park, N., Peterson, C., \& Seligman, M. E. (2006). Character strengths in fifty-four nations and the fifty US states. The Journal of Positive Psychology, 1(3), 118-129. doi: 10.1080/17439760600619567

Peterson, C., \& Park, N. (2004). Classification and measurement of character strengths: Implications for practice. In P. A. Linley, \& S. Joseph (Eds.), Positive psychology in practice (pp. 433-446). New Jersey: John Wiley \& Sons, Inc.

Peterson, C., \& Seligman, M. E. (2004). Character strengths and virtues: A handbook and classification. New York: Oxford University Press.

Proctor, C., Tsukayama, E., Wood, A. M., Maltby, J., Eades, J. F., \& Linley, P. A. (2011). Strengths Gym: The impact of a character strengths-based intervention on the life satisfaction and well-being of adolescents. The Journal of Positive Psychology, 6(5), 377-388. doi: 10.1080/17439760.2011.594079

Proyer, R. T., Gander, F., Wellenzohn, S., \& Ruch, W. (2013). What good are character strengths beyond subjective well-being? The contribution of the good character on selfreported health-oriented behavior, physical fitness, and the subjective health status. The Journal of Positive Psychology, 8(3), 222-232. doi: 10.1080/17439760.2013.777767

Rashid, T., Anjum, A., Lennox, C., Quinlan, D., Niemiec, R. M., Mayerson, D., \& Kazemi, F. (2013). Assessment of character strengths in children and adolescents. In C. Proctor, \& P. A. Linley (Eds.), Research, applications, and interventions for children and adolescents (pp. 81-115). Dordrecht: Springer.

Shoshani, A. (2019). Young children's character strengths and emotional well-being: Development of the character strengths inventory for early childhood (CSI-EC). The Journal of Positive Psychology, 14(1), 86-102. doi: 10.1080/17439760.2018.1424925 
Wagner, L. (2019). Good character is what we look for in a friend: character strengths are positively related to peer acceptance and friendship quality in early adolescents. The Journal of Early Adolescence, 39(6), 864-903. doi: 10.1177/0272431618791286

Wagner, L., \& Ruch, W. (2015). Good character at school: positive classroom behavior mediates the link between character strengths and school achievement. Frontiers in Psychology, 6, 1-13. doi: doi.org/10.3389/fpsyg.2015.00610

Wagner, L., Gander, F., Proyer, R. T., \& Ruch, W. (2020). Character strengths and PERMA: Investigating the relationships of character strengths with a multidimensional framework of well-being. Applied Research in Quality of Life(15), 307-328. doi: $10.1007 \% 2 F s 11482-018-9695-\mathrm{Z}$

Weber, M., \& Ruch, W. (2012). The role of a good character in 12-year-old school children: Do character strengths matter in the classroom? Child Indicators Research, 5(2), 317334. doi: 10.1007/s12187-011-9128-0

Weber, M., Wagner, L., \& Ruch, W. (2016). Positive feelings at school: On the relationships between students' character strengths, school-related affect, and school functioning. Journal of Happiness Studies, 17(1), 341-355. doi: 10.1007/s10902-014-9597-1 